\title{
Optimalisasi Sistem Pemeliharaan Gedung Sekolah Berbasis Partisipasi Masyarakat (Studi Kasus: SDN 16 Meulaboh)
}

\author{
Edi Mawardi ${ }^{*}$, Bambang Tripoli ${ }^{2}$, Samsunan $^{3}$, Herza Zifra $^{4}$ \\ ${ }^{1,2,3,4}$ Program Studi Teknik Sipil, Fakultas Teknik, Universitas Teuku Umar, Meulaboh - Aceh
}

*Koresponden email: edimawardi@utu.ac.id

Diterima: 7 September 2021

Disetujui: 12 Oktober 2021

\begin{abstract}
School building infrastructure needs maintenance and thi is not only carried out by the government but also involve community. The purpose of this study was to determine the existing condition of the school building and the efforts of community participation in building maintenance. This research was conducted at the SD 16 Meulaboh. Methods of data collection by field observations, interviews and distributing questionnaires to the school community (the community around the school, students, teachers, and school administrators). Data processing used a Likert scale, then classifying it into three categories, the first is the low with a score below 46, the medium scores between 46 - 76, and the high is more than 76. Meanwhile, the results of interviews and observations were analyzed using descriptive methods. The results of the study on the existing condition of the school building in a slightly damaged condition where the damage occurred only to non-structural components, namely floor coverings, infill walls, as well as doors and windows. The results were divided into two groups, namely residents and students, citizen participation in the medium category reached 7 people $(12.07 \%)$ while high participation reached 51 people $(87.93 \%)$. Student participation in the medium category reached 4 people $(10.00 \%)$, while high participation reached 36 people $(90.00 \%)$. This shows that the community of SD Negeri 16 Meulaboh has a high participation in the routine maintenance of the school building.
\end{abstract}

Keywords: maintenance, school buildings, questionnaire, community participation, likert scale

\begin{abstract}
Abstrak
Infrastruktur bangunan sekolah perlu pemeliharaan dan pemeliharaan tidak hanya dilakukan oleh pemerintah tetapi bisa juga melibatkan masyarakat. Tujuan dari penelitian ini untuk mengetahui kondisi eksisting bangunan sekolah dan upaya partisipasi masyarakat terhadap pemeliharaan gedung. Penelitian ini dilakukan di gedung sekolah Dasar Negeri 16 Meulaboh. Metode pengumpulan data dengan observasi lapangan, wawancara serta penyebaran kuesioner terhadap masyarakat sekolah (masyarakat sekitar sekolah, murid, guru, dan para pengelola sekolah). Pengolahan data kuesioner menggunakan skala likert, kemudian mengklasifikasikan menjadi tiga tingkat kategori, yang pertama kategori rendah skor dibawah 46, kategori sedang skor diantara 46 - 76, dan kategori tinggi lebih dari 76. Sedangkan hasil wawancara dan observasi dilapangan dianalisis menggunakan metode deskriptif. Hasil penelitian tentang kondisi eksisting gedung sekolah dalam kondisi rusak ringan dimana kerusakan terjadi hanya pada komponen non struktural yaitu pada penutup lantai, dinding pengisi, serta pintu dan jendela. Hasil partisipasi dibagi menjadi dua kelompok yaitu warga dan murid, hasil partisipasi warga memiliki kategori sedang mencapai 7 orang $(12,07 \%)$ sedangkan partisipasi tinggi mencapai 51 orang $(87,93 \%)$. Partisipasi siswa memiliki kategori sedang mencapai 4 orang $(10,00 \%)$, sedangkan partisipasi tinggi mencapai 36 orang $(90,00 \%)$. Hal ini menunjukkan bahwa masyarakat Sekolah Dasar Negeri 16 Meulaboh memiliki partisipasi tinggi dalam pemeliharaan rutin gedung sekolah.
\end{abstract}

Kata Kunci: pemeliharaan, gedung sekolah, kuesioner, partisipasi masyarakat, skala likert

\section{Pendahuluan}

Gedung sekolah memiliki fungsi yang sangat penting dalam pengembangan pendidikan suatu wilayah dan upaya mewujudkan dimana bangunan sekolah digunakan sebagai prasarana pendidikan [10]. Dengan tersedianya bangunan gedung sekolah akan sangat mendukung perkembangan dalam bidang pendidikan [11]. Gedung yang kurang mendapatkan pemeliharaan atau perawaatan bisa diyakini akan lebih cepat mengalami kerusakan [1]. Apabila kerusakan kecil tidak segera dilakukan perbaikan maka kerusakan lebih besar dan menyebar pada bagian lainnya dan kerusakan tersebut menjadi semakin parah[2]. 
Menurut E. Mawardi, konsep pemeliharaan harus dilakukan secara terencana sesuai dengan spesifikasi bahan yang dipakai dan disesuaikan dengan kondisi lingkungan yang mungkin mempengaruhi selama masa pakainya [3]. Pemeliharaan pada bangunan harus diberikan secara dini dan teratur guna mencegah kerusakan pada bagian komponen lainnya[8]. Adapun komponen konsep pemeliharaan dan perbaikan yang dapat dilakukan berupa pemeliharaan (maintenance), perbaikan ringan (repairing) dan perbaikan dengan perkuatan (strengthening) [7].

Sekolah Dasar merupakan jenjang pendidikan dasar yang berfungsi sebagai dasar-dasar keilmuan dan membantu mengoptimalkan perkembangan anak [9]. Sekolah Dasar Negeri 16 Meulaboh Kabupaten Aceh Barat berlokasi di jalan Teuku Dipancu Desa Blang Beurandang Kecamatan Johan Pahlawan, penyelenggaraan pendidikan yang berkualitas tentu tidak terlepas dari infrastruktur yang mendukungnya, termasuk bangunan gedung sekolah sebagai prasarana utama tempat belajar siswa. Sebagai usaha penyediaan prasarana sekolah yang memadai, perlu dilaksanakan pemeliharaan, karena bangunan sekolah termasuk dalam fungsi sosial dan budaya, maka sekolah bukan hanya milik Dinas Pendidikan tetapi milik masyarakat sekolah [9].

Untuk itu perlu adanya pemeliharaan berbasis partisipasi masyarakat untuk fasilitas umum [4]. Dimana yang dimaksud warga sekolah adalah kepala sekolah, komite sekolah, guru, siswa, masyarakat sekitaran sekolah, penjaga sekolah [9]. Berdasarkan masalah di atas, dapat di identifikasi salah satu penyebab terjadinya kerusakan gedung adalah kurangnya atau tidak dilaksanakannya pemeliharaan yang baik oleh pihak sekolah [12]. Tujuan dari penelitian ini untuk mengetahui kondisi eksisting bangunan sekolah dan upaya partisipasi masyarakat terhadap pemeliharaan gedung[6].

\section{Metode Penelitian}

\section{Tempat dan waktu penelitian}

Penelitian ini dilakukan pada gedung Sekolah Dasar Negeri 16 Meulaboh Kabupaten Aceh Barat berlokasi di jalan Teuku Dipancu Desa Blang Beurandang Kecamatan Johan Pahlawan selama 4 bulan (Agustus - November 2020).

Data yang dibutuhkan dalam penelitian menggunakan dua sumber data yaitu data primer dan data sekunder[15]. Variabel-variabel tersebut diukur dengan instrumen penelitian, sehingga data yang terdiri dari angka-angka dapat dianalisis berdasarkan prosedur statistik [5]. Teknik pengumpulan data primer menggunakan beberapa metode, antara lain :

a. Metode pengamatan (observasi), digunakan untuk melihat secara langsung kondisi eksisting gedung SD Negeri 16 Meulaboh, sehingga penulis dapat mengkategorikan kerusakan yang terjadi di gedung tersebut;

b. Metode wawancara, dalam penelitian ini dilakukan secara langsung terhadap masyarakat sekolah dan sekitaran sekolah;

c. Metode kuesioner, dalam penelitian ini kuesioner dibagikan kepada masyarakat sekolah yang dibagi menjadi dua kategori yaitu kategori warga dan kategori murid.

Data sekunder yang digunakan merupakan denah sekolah, luas sekolah, jumlah ruang kelas, jumlah masyarakat, siswa dan guru.

Teknik pengambilan sampel pada penelitian ini menggunakan rumus Slovin dengan jumlah populasi 4.632, dimana jumlah penduduk pada Desa Blang Beurandang/masyarakat sekitar sekolah 4.387, jumlah siswa/siswi 220, jumlah guru 23, kepala sekolah, komite sekolah dan penjaga sekolah, maka jumlah sampel yang didapat adalah[14] :

$$
\mathrm{n}=\frac{4.387}{4.387 \times(10 \%)^{2}+1}=97,777 \approx 98
$$

Perhitungan diatas menjelaskan, jumlah sampel yang digunakan adalah sebanyak 98 responden. Dimana sampel tersebut akan dibagikan kepada warga sekolah diantaranya 35 orang untuk masyarakat sekitar sekolah, 40 untuk siswa kelas V dan VI, 20 untuk guru sekolah, kepala sekolah, komite sekolah dan penjaga sekolah.

Metode yang digunakan adalah metode analisis deskriptif kuantitatif yang didukung dengan analisa kualitatif [13]. Metode ini digunakan untuk melihat kondisi eksisting gedung Sekolah Dasar Negeri 16 Meulaboh dan mengkaji bagaimana partisipasi masyarakat sekolah SD Negeri 16 Meulaboh. Daftar pertanyaan yang akan diajukan kepada responden disusun dengan menggunakan Skala Likert alternatif jawaban yang sekiranya sesuai dengan pendapat, pengetahuan dan pandangan dari responden. Untuk 
mempermudah di dalam menganalisa jawaban responden maka peneliti mengkategorikan beberapa tingkat dalam skala dan membagi responden menjadi dua golonganya itu warga dan murid/siswa.

Teknik analisis data yang digunakan yaitu (1) pengumpulan data; (2) analisis data; (3) menghitung skor jawaban menurut tingkat skala; dan (4) membuat grafik partisipasi masyarakat sekolah.

\section{Hasil dan Pembahasan}

\section{Analisis perhitungan}

Kondisi eksisting Sekolah Dasar Negeri 16 Meulaboh dalam kondisi rusak ringan dan partisipasi warga sekolah dengan persentase tertinggi $87,93 \%$, untuk partisipasi murid dengan persentase $90,00 \%$. Hal ini menujukkan bahwa masyarakat SD Negeri 16 Meulaboh ikut berpartisipasi dalam pemeliharaan gedung sekolah.

Analisis data partisipasi masyarakat dalam tiga kategori jenjang adalah sebagai berikut :

1. Rentang maksimum $=$ skor tinggi $\mathrm{x}$ jumlah pertanyaan

$$
=5 \times 20
$$

$$
=100
$$

2. Rentang minimum $=$ skor rendah $x$ jumlah butir pertanyaan

$=1 \times 20$

$$
=20
$$

3. Luas jarak sebaran $=$ rentang maksimum - minimum

$$
=100-20
$$

$$
=80
$$

4. Satuan deviasi $=80 / 5$

$$
=16
$$

5. Mean teoritis $=\frac{\text { skor } \text { maksimum }+ \text { skor minimum }}{2}$

$$
=\frac{100+20}{2}=60
$$

6. Menggolongkan subjek atau jawaban ke dalam 3 kategorisasi diagnosis tingkat kinerja, yaitu sebagai berikut :
$\mathrm{X}>(\mu-1,0 \sigma)$
Partisipasi rendah
$(\mu-1,0)<X<(\mu+1,0)$
Partisipasi sedang
$(\mu+1,0)<X$
Partisipasi tinggi

Langkah selanjutnya, memasukkan nilai $\mu$ dan o ke dalam kategorisasi tersebut diatas.

1. Untuk kategori partisipasi rendah

$$
\begin{aligned}
& X<(\mu-1,0 \sigma) \\
& X<(60-1,0 \times 16) \\
& X<(60-16) \\
& X<46 \text { (skor kurang dari } 46 \text { kategori partisipasi rendah) }
\end{aligned}
$$

2. Untuk katagori partisipasi sedang.

$$
\begin{aligned}
& (\mu-1,0 \sigma) \leq \mathrm{X}<(\mu+1,0 \sigma) \\
& (60-1,0 \times 16) \leq \mathrm{X}<(60+1,0 \times 15) \\
& (60-1,0 \times 16) \leq(60+16) \\
& 46 \leq \mathrm{X}<76 \text { (skor } 46-76 \text { kategori partisipasi sedang) }
\end{aligned}
$$

3. Untuk kategori partisipasi tinggi

$$
\begin{aligned}
& (\mu+1,0 \sigma) \leq X \\
& 69+1,0 \times 16) \leq X \\
& (60+16) \leq X \\
& 76 \leq X \text { (skor } 76 \text { ke ataspartisipasi tinggi) }
\end{aligned}
$$

Perhitungan di atas, dapat diambil kesimpulan sebagai mana ditampilkan dalam Tabel 1.

Tabel 1. Kategori partisipasi

\begin{tabular}{ccc}
\hline Rendah & Sedang & Tinggi \\
\hline Skor yang kurang dari 46 & Skor diantara 46 - 76 & Skor diatas 76 \\
\hline & Sumber: Analisa data (2020) & \\
& 2350 &
\end{tabular}




\section{Analisis partipasi warga}

Peneliti menganalisis 58 reponden mengenai partisipasi mereka dalam memelihara gedung sekolah, hasil analisis partisipasi tersebut terlihat pada Tabel 2.

Tabel 2. Klasifikasi/kategori partisipasi warga dalam pemeliharaan gedung sekolah

\begin{tabular}{clcc}
\hline No. & Kategori Partisipasi Masyarakat & Jumlah & Persentase \\
\hline 1. & Partisipasi rendah & - & - \\
2. & Partisipasi sedang & 7 & 12,07 \\
3. & Partisipasi tinggi & 51 & 87,93 \\
\hline \multicolumn{5}{c}{ Jumlah } & 58 & 100 \\
\hline \multicolumn{2}{c}{ Sumber: Pengolahan data (2020) }
\end{tabular}

Berdasarkan Tabel 2, maka dapat diketahui bahwa klasifikasi partisipasi masyarakat dalam pemeliharaan gedung sekolah sangat baik. Tidak ada seorangpun masyarakat yang memiliki partisipasi rendah. Partisipasi masyarakat yang memiliki kategori sedang mencapai 7 orang $(12,07 \%)$. Sedangkan masyarakat yang memiliki partisipasi tinggi mencapai 33 orang $(87,93 \%)$. Hal ini menunjukkan bahwa masyarakat sekolah SD Negeri 16 Meulaboh berpartisipasi aktif dalam menjaga gedung sekolah. Peneliti menggambarkan partisipasi masyarakat dalam bentuk grafik seperti yang terlihat pada Gambar 1.

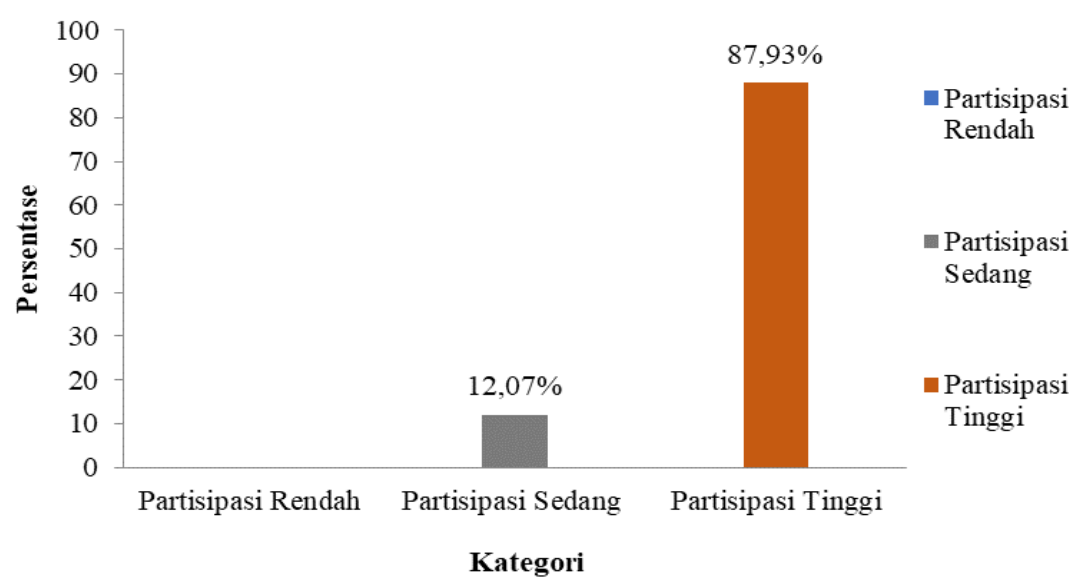

Gambar 1. Grafik persentase partisipasi warga Sumber : Pengolahan data (2020)

Berdasarkan grafik pada Gambar 1, maka dapat diketahui bahwa partisipasi warga sekolah Dasar Negeri 16 Meulaboh sangat tinggi dalam menjaga eksistensi gedung sekolah. Warga menyadari betapa pentingnya untuk menjaga gedung sekolah karena gedung sekolah memiliki fungsi yang sangat penting dalam pengembangan pendidikan suatu wilayah, sehingga masyarakat merasa memiliki sekolah dan berusaha untuk menjaga sekolah agar terus beroperasi. Oleh karena itu, masyarakat berusaha aktif dalam menjaga gedung sekolah.

\section{Analisis partipasi murid}

Peneliti menganalisis 40 murid mengenai partisipasi mereka dalam memelihara gedung sekolah, hasil analisis partisipasi murid seperti terlihat pada Tabel 3.

Tabel 3. Klasifikasi/Kategori partisipasi siswa dalam pemeliharaan gedung sekolah

\begin{tabular}{|c|c|c|c|}
\hline No. & Kategori partisipasi masyarakat & Jumlah & Persentase \\
\hline 1. & Partisipasi rendah & - & \\
\hline 2. & Partisipasi sedang & 4 & 10,00 \\
\hline 3. & Partisipasi tinggi & 36 & 90,00 \\
\hline & Jumlah & 40 & 100 \\
\hline
\end{tabular}

Berdasarkan Tabel 3, dapat diketahui bahwa klasifikasi partisipasi masyarakat dalam pemeliharaan gedung sekolah sangat baik. Dimana setelah melakukan pembobotan pada hasil kuesioner, tidak ada seorang pun siswa yang memiliki partisipasi rendah. Sedangkan siswa yang memiliki kategori tinggi 
mencapai 36 siswa dengan persentase 90\%. Hanya 4 siswa dengan persentase $10 \%$ yang memeliki partisipasi sedang, hal ini menunjukkan bahwa siswa/siswi SD Negeri 16 Meulaboh ikut berpartisipasi menjaga dan ikut memelihara gedung sekolah mereka. Peneliti menggambarkan partisipasi siswa dalam bentuk grafik seperti terlihat pada Gambar 2.

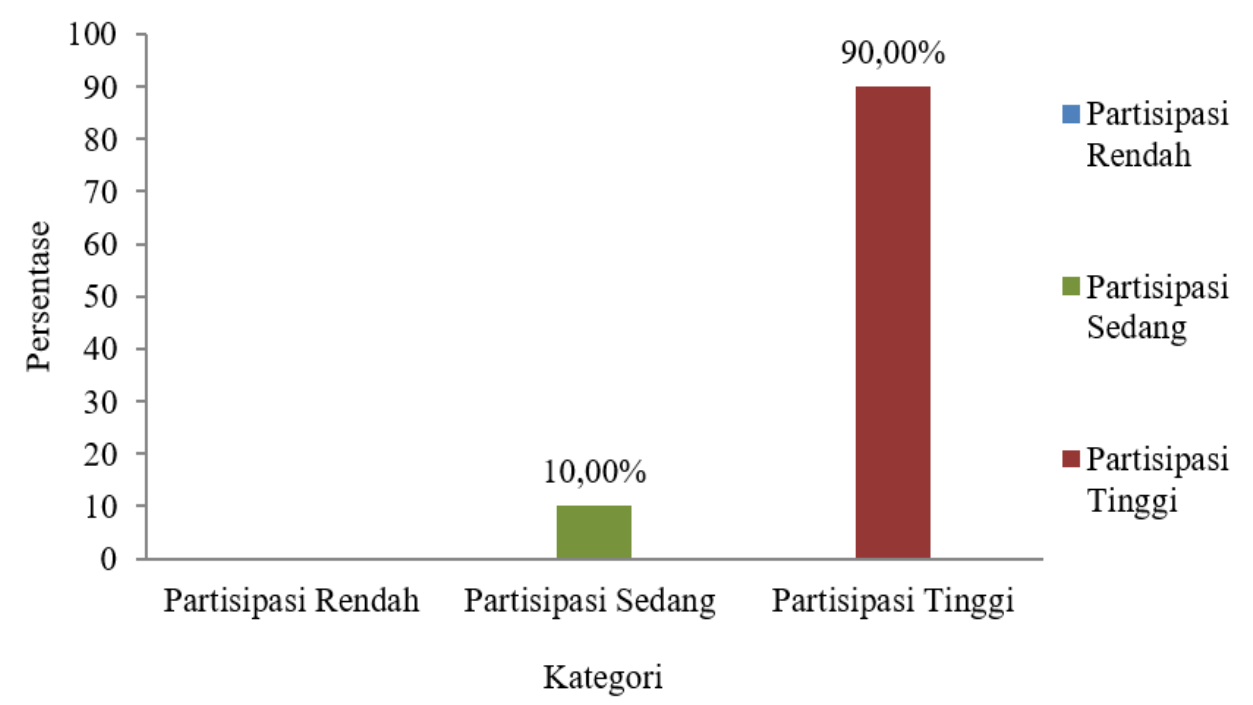

Gambar 2. Grafik persentase partisipasi murid Sumber: Pengolahan data (2020)

Berdasarkan grafik terlihat pada Gambar 2, dapat diketahui bahwa partisipasi siswa sangat tinggi dalam menjaga dan memelihara gedung sekolah. Siswa menyadari pentingnya menjaga gedung sekolah, supaya terjadinya proses belajar mengajar yang nyaman dan kondusif. Oleh karena itu, siswa berusaha aktif dalam menjaga gedung sekolah.

\section{Kesimpulan}

Partisipasi masyarakat golongan pertama umur 20 - 50 (dewasa) memiliki kategori partisipasi sedang mencapai 7 orang $(12,07 \%)$ kemudin masyarakat yang memiliki partisipasi tinggi mencapai 51 orang $(87,93 \%)$. Hal ini menunjukkan bahwa masyarakat SD Negeri 16 Meulaboh ikut berpartisipasi dalam pemeliharaan rutin gedung sekolah.

Partisipasi masyarakat golongan murid/siswa memiliki kategori partisipasi sedang mencapai 4 orang (10\%) kemudian siswa yang memiliki partisipasi tinggi mencapai 36 orang (90\%). Hal ini menunjukkan bahwa siswa SD Negeri 16 Meulaboh ikut berpartisipasi dalam pemeliharaan rutin gedung sekolah. Hasil partisipasi masyarakat golongan murid tidak sesuai dengan apa yang peneliti lihat dilapangan. Karena pada hasil analisis partisipasi siswa sangat tinggi bahkan tidak ada partisipasi rendah sedangkan dilapangan masih ada beberapa bagian yang perlu diperhatikan dan diperbaiki.

\section{Saran}

Berdasarkan hasil penelitian yang telah dilakukan, maka peneliti mengusulkan beberapa saran untuk peningkatan kualitas pendidikan khususnya melalui pemeliharan gedung sekolah. Adapun saran-saran tersebut :

1. Perlu ditingkatkan pemahaman kepada siswa tentang pentingnya keikutsertaan mereka dalam menjaga bangunan gedung sekolah agar tidak ada lagi dinding yang bercoret-coret pintu yang rusak, jendela yang pecah dan lain sebagainya.

2. Partisipasi golongan pertama umur 20 - 50 dewasa sudah sangat baik, untuk itu perlu dipertahankan.

3. Bagi sekolah, diharapkan agar terus meningkatkan pemeliharaan terhadap gedung sekolah agar tidak ada dinding yang bercoretan, lantai keramik yang pecah, jendela yang pecah dan pintu yang rusak. Supaya gedung sekolah nyaman dan aman saat digunakan untuk proses pembelajaran.

4. Bagi peneliti lainnya, agar melakukan penelitian lainnya yang berkaitan dengan partisipasi masyarakat dalam pendidikan yang tidak dibahas dalam penelitian ini, seperti keterlibatan dalam pengawasan kualitas pendidikan dan aspek lainnya dalam pendidikan. 


\section{Daftar Pustaka}

[1] Departemen Pekerjaan Umum No. 24 Tahun 2008 tentang Pedoman Pemeliharaan dan Perawatan Bangunan Gedung, Jakarta.

[2] E. Mawardi, Samsunan, dan F. Faturrahman, Kajian Pemeliharaan Rutin pada Gedung Rektorat Universitas Teuku Umar, Teras Jurnal Teknik Sipil, Vol. 10 (1), hal.100-109, 2020.

[3] E. Mawardi, T. B. Aulia, dan A. Abdullah, Kajian Konsep Operasional Pemeliharaan Gedung SMA Bina Generasi Bangsa Meulaboh Aceh Barat, Jurnal Teknik Sipil, Vol. 1 (4), 2018.

[4] Islamiah, Tingkat Partisipasi Masyarakat dalam Pembangunan di Desa Sanglepongan Kecamatan Curio Kabupaten Erengkang, Skripsi, Universitas Islam Negeri Alauddin, Makassar, 2018.

[5] J. Noor,Metodologi Penelitian, Penerbit Kencana Prenada Media Group, Jakarta, 2012.

[6] M. Navira, Kajian Sistem Manajemen Operasional Museum Tsunami Aceh, Jurnal Teknik Sipil, Pascasarjana Universitas Syiah Kuala, Vol. 3 (2), 2014.

[7] Mulyandari, Hestin, dan R. A. Saputra, Pemeliharaan Bangunan: Basic Skill Facility Management, Yogyakarta: Andi, Yogyakarta, 2011.

[8] O. Rita, Optimalisasi Sistim Pemeliharaan Gedung Pada Bangunan Penyelamat (Escape Building) di Kota Banda Aceh, Tesis, Universitas Syiah Kuala, Banda Aceh, 2015.

[9] Petunjuk Teknis Pemeliharaan dan Perawatan Aset Sarana-Prasarana Sekolah Bersama Masyarakat, Dencentralized Basic Education (DBE-I)-USAID, Jakarta, 2010.

[10] Pemerintah Republik Indonesia, 2002, Undang-undang Republik Indonesia Nomor 28 Tahun 2002 Tentang Bangunan Gedung, Jakarta.

[11] Rencana Statetegi kementrian Pendidikan dan Kebudayaan 2020-2024, Jakarta, 2020

[12] Rosalina, Sistem Pemeliharaan Gedung Ditinjau dari Keandalan Bangunan Gedung, Studi Kasus Gedung Rumah Susun Sederhana Sewa di Kabupaten Cilacap, Tesis, Universitas Sebelas Maret, Surakarta, 2011.

[13] Sudjana, Metode Statistika, Ganesa Exact, Bandung, 2015.

[14] Sugiono, Metode Penelitian Kuantitatif, Kualitatif dan R dan D, CV. Alfabeta, Bandung, 2010.

[15] S. Arikunto, Prosedur Penelitian Suatu Pendekatan Praktik, Cetakan ke-14, PT. Rineka Cipta, Jakarta, 2010. 